\title{
Biomechanical future of the growing pulmonary autograft in Ross operation
}

\author{
Francesco Nappi ${ }^{1}$, Sanjeet Singh Avtaar Singh ${ }^{2}$, Christophe Acar ${ }^{3}$ \\ ${ }^{1}$ Cardiac Surgery Centre Cardiologique du Nord de Saint-Denis, Paris, France; ${ }^{2}$ Department of Cardiac Surgery Golden Jubilee National Hospital, \\ Glasgow, UK; ${ }^{3}$ Department of Cardiovascular Surgery, Hospital de la Salpétrière, Paris, France \\ Contributions: (I) Conception and design: F Nappi, C Acar; (II) Administrative support: F Nappi, C Acar; (III) Provision of study materials or patients: \\ F Nappi, C Acar; (IV) Collection and assembly of data: All authors; (V) Data analysis and interpretation: F Nappi, C Acar; (VI) Manuscript writing: \\ All authors; (VII) Final approval of manuscript: All authors. \\ Correspondence to: Francesco Nappi, MD. Cardiac Surgery Centre Cardiologique du Nord de Saint-Denis, 36 Rue des Moulins Gémeaux, 93200 \\ Saint-Denis, France. Email: francesconappi2@gmail.com.
}

\begin{abstract}
It has been few years since the preliminary translational research study on mechanics performance of autologous pulmonary tissue were published to circumvent complication relies to SVD. Several studies reported the modification of pulmonary native autograft root subjected to dynamic stress strain in long-term outcomes of aortic valve replacement. Our multidisciplinary research team firstly describe the weave relationship between stress-strain, growth and remodelling in an experimental model of Ross Operation. From a biomechanical point of view, the rapid absorption of polydioxanone constituting the internal part of the device may limit the potential negative effect of excessive stretching and improvement of steeper curve in the circumferential response. Improvement of longitudinal stretching of pulmonary autograft by external component of device are indicative of auxetic effect of e-PTFE. Successful reinforcement with semiresorbable device can also be favourable to pulmonary autograft function in growing patients needing to match somatic growth. The attendant decrease in PA expansion and the preserved features of the valve leaflets enhances durability of Ross operation. Strengthening of the distal pulmonary root anastomosis using external reinforcement, modifying the ascending phase of the circumferential stress curve, might be advisable as previously described. PA is an ideal substitute for aortic valve replacement not only in Mr. Ross's dreams but also from the biomechanical point of view.
\end{abstract}

Keywords: Ross operation; Ross biomechanics; pulmonary autograft expansion

Submitted Sep 03, 2019. Accepted for publication Dec 31, 2019.

doi: $10.21037 /$ tp.2020.03.02

View this article at: http://dx.doi.org/10.21037/tp.2020.03.02

\section{The clinical problem}

The use of pulmonary autograft (PA) has been widely adopted for aortic valve disease in children and young adults. The majority of patients currently receive a PA due to its ability to match the somatic growth of cardiovascular structures in pediatric surgery alongside avoidance of life-long anticoagulation treatment (1). In the adult population, the use of PA is indicated for surgical treatment of bicuspid aortic valve, which is, the most common congenital heart pathology, affecting $1.3 \%$ of the population worldwide (2). Resistance among surgeons to using the pulmonary autograft in the aortic position is due to the ever-present risk of dilatation. Accordingly, the clinical benefit of using autologous tissue is hampered by the negative effect caused by systemic-pressure load associated with structural or non-structural deterioration of the valve substitute in the right ventricular outflow tract. Experimental studies highlight the various segments of the neo-aorta which have differing potentials for dilation, with the neo-valsalva sinuses and neo-sinutubular junction being the most frequently affected $(3,4)$. The consequence is PA 

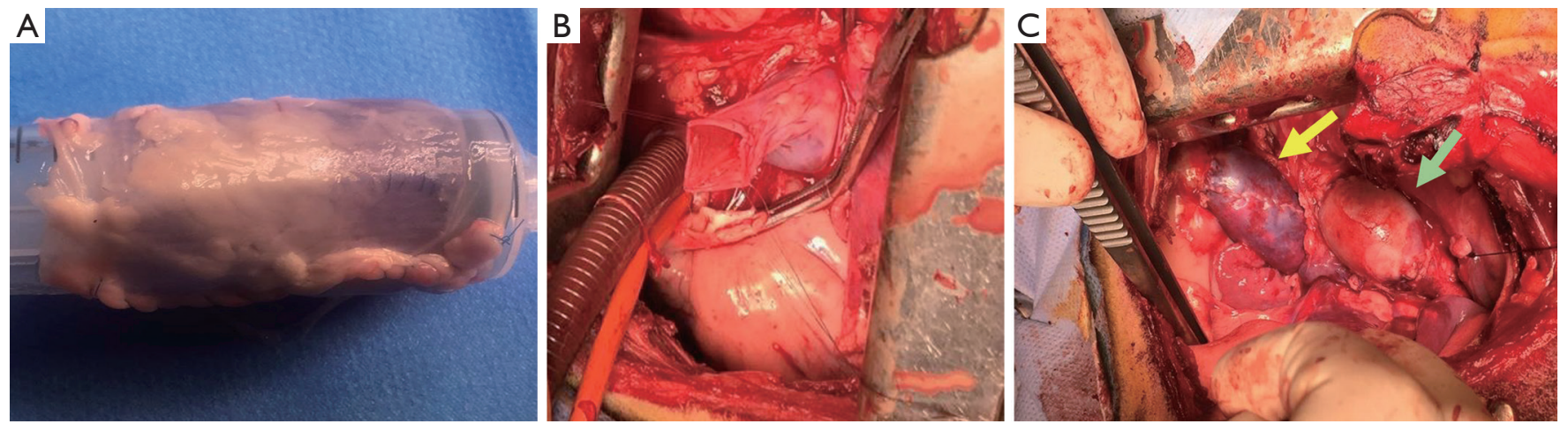

Figure 1 Right ventricle outflow tract was reconstructed with a native pericardial neoconduit. (A) Neopulmonary artery made with native pericardium; (B) right ventricle outflow tract. Proximal anastomosis; (C) pulmonary artery (yellow arrow). Pulmonary autograft transposed without reinforcement (green arrow).

regurgitation leading to severe left ventricular dysfunction, a daunting issue in the long-term outcomes of patients who had surgery for congenital and acquired heart disease (5).

To elude this issue, a structural modification of the PA conduit in the early post-implantation phase would be desirable in order to match the increased pressure load requirements and possibly recreate similar elastomechanical and functional properties of the native aorta.

In our line of research, we reinforced the autologous tissue (PA conduit) with a composite semi-resorbable armoured prosthesis, which is then able to mechanically support the pulmonary autograft, preventing expansion and gradually complementing the pulmonary autograft morpho-structure. Inadvertently, we induced progressive arterial-like tissue remodelling $(6,7)$. We further revealed the mechanisms of growth, remodelling and stress shielding of the reinforced PA through a large animal experimental model supported by an ex vivo mathematical and physical model (8).

\section{What has the biomechanics of the growing PA taught us?}

In order to elucidate the mechanisms underlying PA dilation and evaluate possible strategies to prevent complications, we developed a large animal model of then Ross operation (6). Even if technical issues and anatomical constraints prevented the realization of a complete Ross procedure, we were able to reliably reproduce the pressure-load sustained by the PA when transposed into the systemic arterial system. Briefly, experiments were performed in growing lambs, under cardiopulmonary bypass, and the PA conduit was used as a graft that was inserted in the descending aorta while the right ventricle outflow tract was reconstructed with a fresh homograft from another lamb of the same age and weight or native pericardial neoconduit (Figure 1). We observed the growth of the animal from 2 to 6 months, evaluating the augmentation of autograft diameter during the phase of fastest growth when the weight of the animal progressed from an average of $20 \mathrm{~kg}$ to an average of $60 \mathrm{~kg}$ (6-8).

The experimental study also comprised of a group which received reinforcement by means of an external semi-absorbable armored prosthesis wrapped around the pulmonary autograft before implantation to circumvent the dilatation process. The semi-absorbable scaffold consisted of an inner layer of Polydioxanone (PDS) and external armour of non-resorbable ePFTE (Figure 2). The scaffold was size to a rectangle of $20 \mathrm{~mm}$ in height, equivalent to the height of the PA, wrapped on a metallic candle, and then arranged with a suture, so as to generate a cylinder with an internal diameter of $10 \mathrm{~mm}(20 \mathrm{~mm}$ height and $10 \mathrm{~mm}$ diameter). The pulmonary autograft was then included in the fibrillar cylinder (Figure $2 A$ ) and sutured at the level of both its margins and that of the prosthetic structure to the PA conduit (Figure 2B). Angiographical and echocardiographical measurements post-implantation and after 6 months were recorded and a histologic evaluation to demonstrate the structural modification of the vessel wall was performed. We observed that the non-reinforced group developed aneurysmal degeneration and intimal rupture. In contrast, we noticed the growth phase of the lamb had a concurrent increase in the diameter without aneurysmal dilation in the reinforced group $(6,9)$. The 

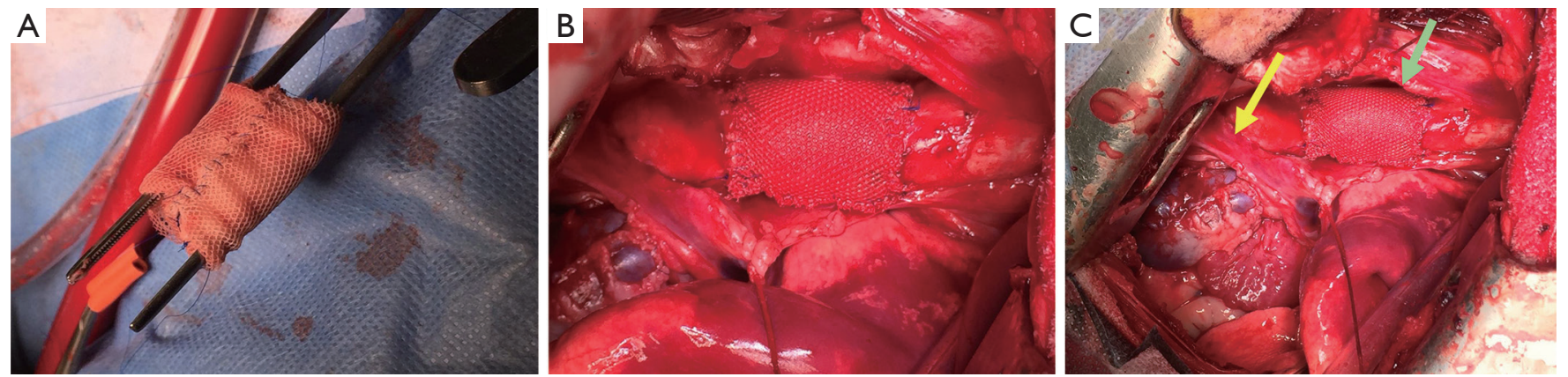

Figure 2 Animal model of Ross operation. (A) Pulmonary autograft with external reinforcement of ePFTE; (B,C) the pulmonary autograft was reimplanted in the descending aorta and reinforced with ePFTE; $(\mathrm{C})$ experimental Ross operation completed. The right ventricle outflow tract was reconstructed with a neopulmonary conduit made with native pericardium (yellow arrow). The pulmonary autograft is transposed in in the systemic pressure regime (green arrow).

histological analysis revealed the ability of the resorbable layer to integrate with the PA morpho-structure and to induce the deposition of a new extracellular matrix, mainly differentiated by the abundant production of elastic fibers $(9,10)$.

At the same time, we matched the acquisition of the information using a physical-mathematical system suitably drawn to obtain a relationship between the in vivo model and the ex vivo model $(11,12)$. This mathematical model was based on the assumption that from the geometric point of view, a blood vessel can be considered a thick-walled hollow (composite) cylinder, and that each layer according to the tissue microstructure offers a unique elastic anisotropy. These features are reflected in a specific elastic response of composite cylindrical structures subjected to gradual and increasing loading conditions (13). Clearly, the pressure load and growth of vascular structure resulted in large deformations and non-linear mathematical models $(14,15)$.

In our model, the non-reinforced pulmonary autograft drastically expanded during the study period, losing its passing tube-like shape and the symmetrical response to stress. Estimation of wall strain using the Cauchy theorem revealed that the circumferential (hoop) strains in the middle layer of the PA wall with peaks measured at $800 \mathrm{kPa}$. This estimate is significantly higher and can bring the tissue stress threshold to a level determining critical mechanical states prior to aneurysmal degeneration. An analysis of the pressure-diameter curve confirmed a non-linear behaviour demonstrating a loud expansion for a range of inflation pressures as low as $50 \mathrm{mmHg}$. In our predictive model, the external diameter of the PA achieved pathological dimensions well before the curve exhibited its theoretical hardening $(9-12,16,17)$.
We evaluated this effect on the behavior of the PA conduit by adding a semi-absorbable reinforcement and highlighted the differences. As demonstrated in previous studies and confirmed by current research, the reinforcement consisted of a resorbable material, which has been shown histologically to have the ability to integrate with the intermediate layer of pulmonary autograft causing the production of a new extracellular matrix with a high quantity of elastic fibers. The entire scaffolding is reinforced with ePFTE, which is an auxetic material distinct from a Poisson index of -2 to confer the mechanical-physical property of "close and up". The crosslinked prosthesis is conceived by several repeated elements progressively shifting from a "dormant" unstretched configuration to a dilated and rigid one with the intention of driving the growth process and supporting the different grades of pressure loading. These features significantly affected the mathematical outlines (Figure 3). Overall, the prosthesis exercised a "relay race" type action because it guarantees the handover of the bearing structure functions from the PDS scaffold (at the early stages of tissue growth and remodeling) to the e-PTFE armor. In fact, this is initially "dormant" as a consequence of the typically low stiffness manifested by stressfree auxetic structures at minimal strain (Figure 4). Although the mechanical shielding of the lapse vessel works to decrease the radial expansion, it simultaneously allowed the pulmonary artery to remodel its morphostructure to reach a relevant level of mechanical properties. This synergy is due to the fact that the PDS layer induced neoarterialization in the middle layer of the pulmonary autograft, which normally consists of a venous-like structure thereby conferring an increase in wall thickness. After the 

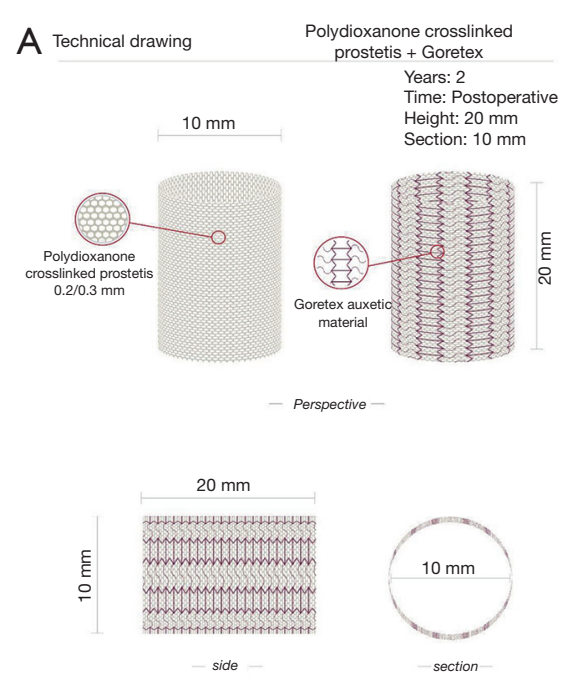
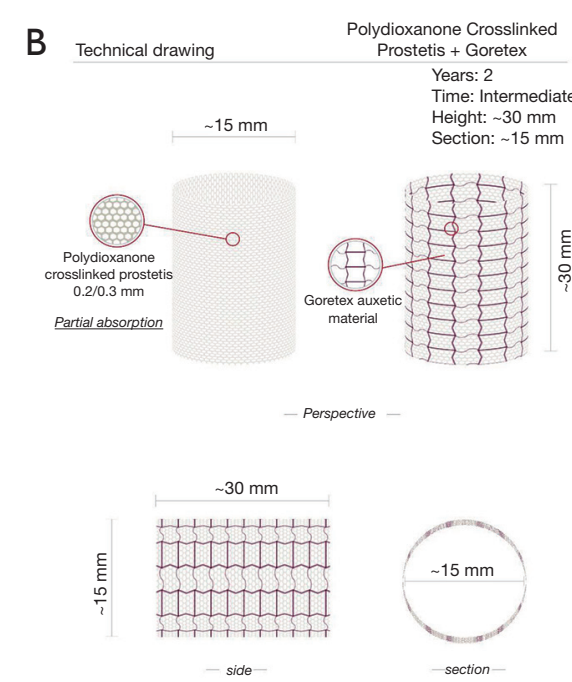
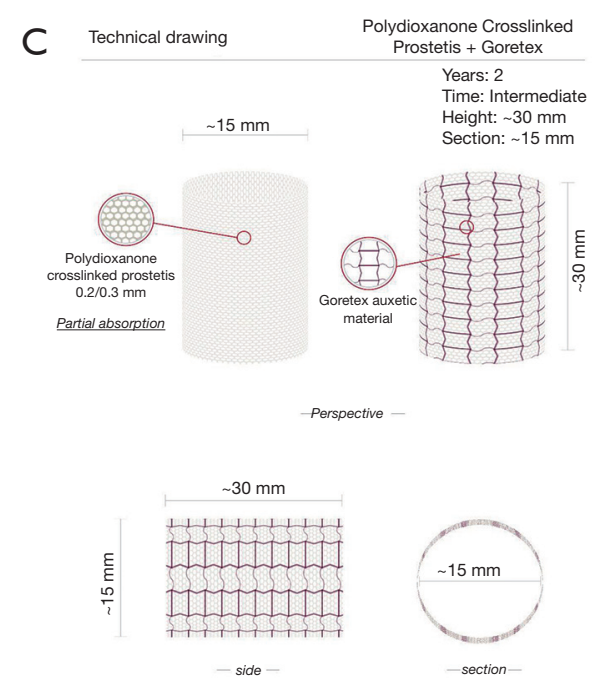

Figure 3 Concept and design of composite semi-resorbable armored bioprosthesis. Figure is schematically explaining the action of stressshielding exerted by the scaffold (see text). The specific design of the ePFTE armor will allow multidirectional growth and resistance to dilatation (see text). The particular weave of the superior part of the armor (left) will progressively adapt and functionally compensate the characteristics of autograft growth. (A) Initial implantation; (B) intermediate phase; (C) complete development. Note the progressive resorption of the resorbable layer and the progressive expansion of the elements composing the mesh made by the auxetic material (ePTFE). Going from A to $\mathrm{C}$ over time, once the bioresorbable scaffold has completed its degradation program and strengthened the vessel walls, the e-PTFE structure took over in the process accompanying the PA media and adventitia toward their progressive aortic somatic growth while sustaining the pressure load. In fact, by stretching its weave from a "dormant" unstretched configuration the ePTFE layer gained stiffness and effectively confined further vessel expansion, avoiding tissue prolapse and aneurysmal degenerative phenomena.

completion of the degradation program and strengthening of vessel walls, the bioabsorbable scaffold can actively react to the increasing systolic pressure by means of e-PTFE structure. The e-PTFE's role combines the second phase of the process that accompanies the tunica media and adventitia of PA conduit towards their progressive aortic somatic growth. In fact, by stretching its weave the ePTFE layer gained stiffness and effectively prevented further vessel expansion, avoiding tissue prolapse and aneurysmal degenerative phenomena (Figure 4).

With sensitivity analysis we have shown that the stress profiles and the difference in effective pressures between the internal systolic thrust and the limitation of the external reinforcement are evident; such that the prosthesis has a stress shielding effect that keeps the distribution of stress on the pulmonary autograft thickness sufficiently uniform (9-12) (Figure 4). During the analysis of the deformation level, the reinforcement allowed maintenance of a moderate stress level in the middle layer of the PA conduit with respect to the native physiological reference rate of the aorta (ticker and more rigid), reaching a safe state of stress set at about $100 \mathrm{kPa}$. On the other end, with the same sensitivity analysis performed on non-reinforced PA, we observed that the pressure-diameter curves had a much smaller range of variations in the outer diameter, within the same pressure interval. Our explanation to this phenomenon lies in the fact that in the reinforced PA conduit, the initial rigid behavior can be attributed to the balance between the internal thrust and the external pressure exerted by the e-PTFE. It is related to the ePTFE elastic reaction to vessel expansion. Subsequently, we observed the presence of an approximately proportional expansive region, followed by an elastic hardening at higher pressures. The explanation of this behavior is due to the combined effect of the mechanical properties of the neo-pulmonary autograft, depending on the new morphology which is related to the stress levels and to the reorientation and distribution of the elastic fibers as well as to the increasing rigidity of the auxetic material induced by the severely expanded elements of the armor (9-12) (Figure 4).

\section{Future direction and areas of uncertainty}

Overall the present study of the biomechanics of the 

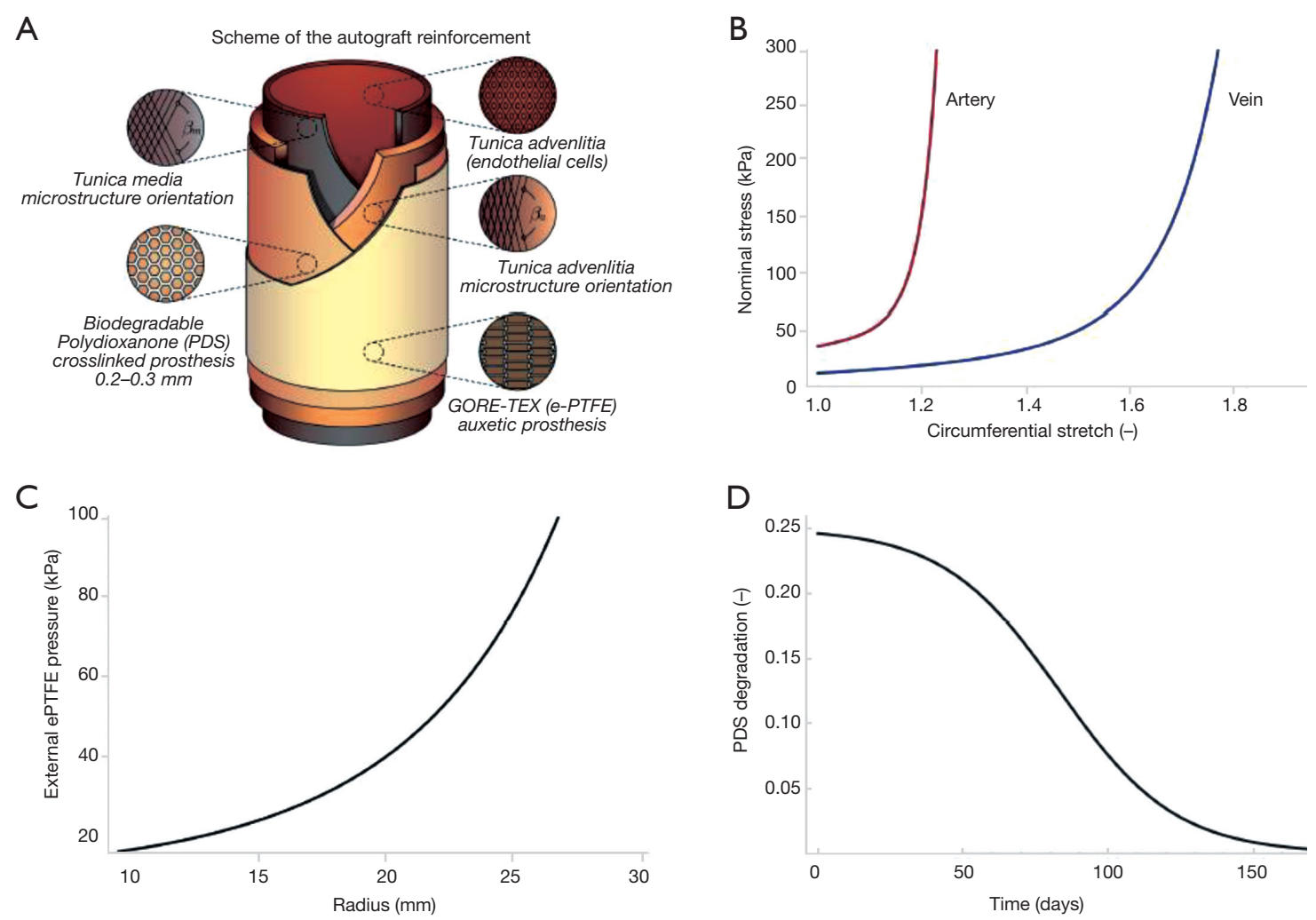

Figure 4 Figure shows (A) sketch of the main biomechanically relevant features of the pulmonary autograft and the reinforcement; (B) nominal (first Piola-Kirchhoff) hoop stress versus circumferential stretch in artery and vein-like materials; (C) elastic reaction pressure against external vessel radius dilation exhibited by ePTFE auxetic reinforcement during pulmonary autograft growth and deformation; (D) in-time mass degradation of bioresorbable polydioxanone (PDS) structure. Adapted from Nappi et al.

pulmonary autograft might provide several insights and perspectives on the long-term clinical benefit of Ross procedure and pave the way for the use of bioresorbable reinforcements during the Ross operation.

Although the use of prosthetic Dacron grafts with an artificial aortic root configuration (Valsalva graft) as external reinforcement of the PA has been advocated by Carrel et al. $(18,19)$ this new surgical strategy had a notably poor biomechanical assessment to detect significant differences in the frequency of clinical events. Although this approach aims at avoiding neoaortic root dilatation thus, guaranteeing the dynamic function of Valsalva sinuses, the role of a rigid Dacron graft to improve clinical outcomes remains unknown. Our experience has shown that the use of synthetic inelastic material is advantageous in preventing the dilatation of the pulmonary autograft subjected to unusual blood pressure, but these poorly deformable materials have a serious negative effect on pulsatility and compliance of the pulmonary autograft. When the autograft is engaged in a straight Dacron prosthetic graft, its ability to match the somatic growth of patients would be extremely limited, depriving physiological and somatic growth of the PA conduit (20-22). We previously demonstrated that the aortic wall compressed by the Dacron graft or other synthetic polyesters not only severely impair its compliance ${ }^{12}$ but provokes a strong inflammatory reaction with significant damage to the vessel of the reinforced PA conduit $(23,24)$. Our studies also showed an improvement in the biomechanical behaviour of the reinforced pulmonary autograft using resorbable materials which integrates within the PA morpho-structure. This concept is biologically plausible and is directly supported by the fact that resorbable polyester may facilitate the PA remodelling and the physiological process of growth in vascular structures (20).

This last point is significant when these considerations are translated into the clinical setting as a guide for cardiologists for the indication of using pulmonary 
autografts to treat severe disease of aortic valve and LVOT $(16,17)$. The use of the Ross operation is recommended in children and young adults. However, the use of this procedure at earlier stages in life is known to be associated with an increased incidence of PA dilation and degeneration $(1,25)$. Thus, one reason for the wider use of reinforcement strategies is to circumvent these complications in children and young adults. In this category of patients, the advantages are compounded by negating the need for life-long anticoagulant drugs, superior hemodynamic performance of the pulmonary autograft (4) and respect for physiological growth, making them even more in demand (3).

In summary, we believe that instead of 'swallowing' literature with 10 years of clinical follow-up on the Ross operation and its subsequent meta-analysis, a new impetus should be given to basic and translational research to stimulate the development of bio-artificial vascular substitutes and provide an immediate future for the Ross procedure. The future clinical use of pulmonary autograft in the treatment of severe aortic valve disease is a marriage of the knowledge of the synergistic process of growth, vascular remodeling and protection from stress, which occurs when the pulmonary autograft is translated into systemic pressure regimens with a high-stress load.

For the future of Ross Operation less art, more biomechanical science.

\section{Acknowledgments}

Funding: None.

\section{Footnote}

Conflicts of Interest: All authors have completed the ICMJE uniform disclosure form (available at http://dx.doi. org/10.21037/tp.2020.03.02). FN serves as the unpaid editorial board member of Translational Pediatrics from Feb 2019 to Jan 2021. The other authors have no conflicts of interest to declare.

Ethical Statement: The authors are accountable for all aspects of the work in ensuring that questions related to the accuracy or integrity of any part of the work are appropriately investigated and resolved.

Open Access Statement: This is an Open Access article distributed in accordance with the Creative Commons
Attribution-NonCommercial-NoDerivs 4.0 International License (CC BY-NC-ND 4.0), which permits the noncommercial replication and distribution of the article with the strict proviso that no changes or edits are made and the original work is properly cited (including links to both the formal publication through the relevant DOI and the license). See: https://creativecommons.org/licenses/by-nc-nd/4.0/.

\section{References}

1. Mazine A, El-Hamamsy I, Verma S, et al. Ross Procedure in Adults for Cardiologists and Cardiac Surgeons: JACC Stateof-the-Art Review. J Am Coll Cardiol 2018;72:2761-77.

2. de Kerchove L, Rubay J, Pasquet A, et al. Ross operation in the adult: Long-term outcomes after root replacement and inclusion techniques. Ann Thorac Surg 2009;87:95-102.

3. Hörer J, Hanke T, Stierle U, et al. Neoaortic root diameters and aortic regurgitation in children after the ross operation. Ann Thorac Surg 2009;88:594-600; discussion 600.

4. Acar C, Varnous S. In response to kazui t, izumoto h, yoshioka k, kawazoe k. Dynamic morphologic changes in the normal aortic annulus during systole and diastole. J heart valve dis 2006;15:617-21. J Heart Valve Dis 2006;15:843.

5. David TE, David C, Woo A, et al. The ross procedure: Outcomes at 20 years. J Thorac Cardiovasc Surg 2014;147:85-93.

6. Nappi F, Spadaccio C, Castaldo C, et al. Reinforcement of the pulmonary artery autograft with a polyglactin and polydioxanone mesh in the ross operation: Experimental study in growing lamb. J Heart Valve Dis 2014;23:145-8.

7. Nappi F, Spadaccio C, Fouret P, et al. An experimental model of the ross operation: Development of resorbable reinforcements for pulmonary autografts. J Thorac Cardiovasc Surg 2015;149:1134-42.

8. Nappi F, Spadaccio C, Montagnani S, et al. A composite semiresorbable armoured scaffold stabilizes pulmonary autograft after the Ross operation: Mr Ross's dream fulfilled. J Thorac Cardiovasc Surg 2016;151:155-64.e1.

9. Nappi F, Fraldi M, Spadaccio C, et al. Biomechanics drive histological wall remodeling of neoaortic root: A mathematical model to study the expression levels of ki 67, metalloprotease, and apoptosis transition. J Biomed Mater Res A 2016;104:2785-93.

10. Spadaccio C, Rainer A, Mozetic P, et al. The role of extracellular matrix in age-related conduction disorders: a forgotten player? J Geriatr Cardiol 2015;12:76-82.

11. Nappi F, Carotenuto AR, Di Vito D, et al. Stress-shielding, 
growth and remodeling of pulmonary artery reinforced with copolymer scaffold and transposed into aortic position. Biomech Model Mechanobiol 2016;15:1141-57.

12. Nappi F, Carotenuto AR, Cutolo A, et al. Compliance mismatch and compressive wall stresses drive anomalous remodelling of pulmonary trunks reinforced with Dacron grafts. J Mech Behav Biomed Mater 2016;63:287-302.

13. Fraldi M, Carannante F, Nunziante L. Analytical solutions for n-phase functionally graded material cylinders under de saint venant load conditions: Homogenization and effects of poisson ratios on the overall stiffness. Compos B Eng 2013;45:1310-24.

14. Holzapfel GA, Ogden RW. Constitutive modelling of arteries. Proc Math Phys Eng Sci 2010;466:1551-97.

15. Holzapfel GA, Gasser T, Ogden RW. A new constitutive framework for arterial wall cechanics and a comparative study of material models. J Elast 2000;61:1-48.

16. Nappi F, Nenna A, Larobina D, et al. Simulating the ideal geometrical and biomechanical parameters of the pulmonary autograft to prevent failure in the Ross operation. Interact Cardiovasc Thorac Surg 2018;27:269-76.

17. Fraldi M, Spadaccio C, Acar C, et al. Best to Clarify to Avoid Misunderstandings in the Biomechanics of Ross Operation: Parentheses Matter. Ann Thorac Surg 2018;106:641-2.

18. Carrel T. The autograft inclusion: An obligatory step to

Cite this article as: Nappi F, Avtaar Singh SS, Acar C. Biomechanical future of the growing pulmonary autograft in Ross operation. Transl Pediatr 2020;9(2):137-143. doi: 10.21037/tp.2020.03.02 avoid late failure following the ross procedure? J Thorac Cardiovasc Surg 2015;149:S53-54.

19. Carrel T, Schwerzmann M, Eckstein F, et al. Preliminary results following reinforcement of the pulmonary autograft to prevent dilatation after the ross procedure. J Thorac Cardiovasc Surg 2008;136:472-5.

20. Nappi F, Spadaccio C, Al-Attar N, et al. The Ross procedure at the crossroads: lessons from biology: is Dr Ross's dream concluded? Int J Cardiol 2015;178:37-9.

21. Nappi F, Spadaccio C, Chello M, et al. The ross procedure: Underuse or under-comprehension? J Thorac Cardiovasc Surg 2015;149:1463-4.

22. Spadaccio C, Montagnani S, Acar C, et al. Introducing bioresorbable scaffolds into the show. A potential adjunct to resuscitate ross procedure. Int J Cardiol 2015;190:50-2.

23. Spadaccio C, Nappi F, De Marco F, et al. Preliminary in vivo evaluation of a hybrid armored vascular graft combining electrospinning and additive manufacturing techniques. Drug Target Insights 2016;10:1-7.

24. Spadaccio C, Nappi F, Al-Attar N, et al. Old Myths, New Concerns: the Long-Term Effects of Ascending Aorta Replacement with Dacron Grafts. Not All That Glitters Is Gold. J Cardiovasc Transl Res 2016;9:334-42.

25. Raja SG. Ross operation for teenagers: Correct indication determines the long-term outcome/early double valve rereplacement after ross operation. Anadolu Kardiyol Derg 2007;7:335-336; author reply 336. 